\title{
Fibroblast and pre-osteoblast cell adhesive behavior on titanium alloy coated with diamond film
}

\author{
William de Melo Silva*a,b, Camila Amorim Ribeiro ${ }^{a}$, Cleiton Silva Marques ${ }^{b}$, Américo Sheitiro Tabata $^{c}$, \\ Margarida Juri Saeki ${ }^{d}$, Leonardo Iusuti Medeiros ${ }^{e}$, Deilson Elgui de Oliveira ${ }^{b}$
}

\author{
${ }^{a}$ Departamento de Bioprocessos e Biotecnologia, Universidade Estadual Paulista Júlio de Mesquita \\ Filho - UNESP, Rua José Barbosa de Barros, $n^{\circ} 1780$, 18610-30, Botucatu, SP, Brasil \\ ${ }^{b}$ Instituto de Biotecnologia - IBTEC, Faculdade de Medicina de Botucatu, Universidade Estadual \\ Paulista Júlio de Mesquita Filho - UNESP, Botucatu, SP, Brasil \\ 'Departamento de Física, Universidade Estadual Paulista Júlio de Mesquita Filho - UNESP, Faculdade \\ de Ciências, Bauru, SP, Brasil \\ ${ }^{d}$ Departamento de Química e Bioquímica, Universidade Estadual Paulista Júlio de \\ Mesquita Filho - UNESP, Instituto de Biociências, Botucatu, SP, Brasil \\ eDepartamento de Ciências Exatas e Tecnológicas - DCET, Universidade Estadual de \\ Santa Cruz - UESC, Ilhéus, BA, Brasil
}

Received: December 11, 2016; Revised: June 28, 2017; Accepted: July 03, 2017

\begin{abstract}
It is well known that titanium alloys have mechanical strengths comparable to steels, as well as high corrosion resistance. Also, they have the advantage of promoting osseointegration, when used in medical and dental implants. This work aims to describe the adhesion properties of fibroblast and osteoblast cells on the surface of titanium aluminum vanadium alloy (Ti6Al4V). Three different conditions of the surface were investigated: smooth, rough and covered with diamond film. Conventional material characterizations were performed to the film which consisted in: Morphological visualization by scanning electron microscopy, confocal profilometry, X-ray diffraction pattern, Raman backscattering spectroscopy and atomic force microscopy. Biocompatibility tests of Ti6Al4V were performed using primary human fibroblasts and mouse pre-osteoblasts cell line MC3T3-E1. Overall, diamond films deposited on Ti6Al4V showed interesting results of uniformity and protection against cracks on to the surface, reasonable biocompatibility features if compared to uncovered ones, indicating that this film is an alternative for using in health care applications.
\end{abstract}

Keywords: Titanium, Diamond, Adhesive, Cell, Osteoblast, Fibroblast

\section{Introduction}

Titanium alloys have been widely used as prosthesis and implants due to its high resistance to fatigue and strain being superior to corrosion resistance when compared to any stainless steel. These properties are critical for the success of implants performed in health care, since particles and debris generated by wear processes may induce unwanted outcomes, such as inflammatory reactions and neoplasm, eventually ${ }^{1,2}$. For example, it is known that titanium is routinely used to substitute bones, such as ribs, knees, skulls and femur. Alternatively, due to adequate osseointegration and formation of a metal-bone interface (MBI), titanium aluminum vanadium (Ti6A14V) alloy can be used as alternative for direct implantation into bone $\mathrm{e}^{3,4}$. In order to avoid detrimental tissue reactions and implant rejection, MBI must be as biocompatible as possible ${ }^{5}$. Any mismatch between metal implant and surrounding biological tissues causes stress strain state at MBI, adversely affecting tissue remodelling and bone healing ${ }^{6}$. Ideally, all parts and implants intended for use in human or veterinary medicine must be highly resistant to corrosion, fatigue and wear. Wear at the contact points is inevitable in prosthesis and implants, because of that, strategies to reduce its effects are being investigated ${ }^{7}$ by using inert films as like nano and microcrystalline diamond films. In this regard, some studies show promising results with carbon-based films, such as diamond-like carbon ${ }^{6,8}$ and diamond films ${ }^{9}$. The use of very hard film, besides hiding the imperfections of the surfaces, contributes to the decrease of the wear, due improvements in the surface-carrying capacity. Nevertheless, the film must be tested regarding its effects on cells ${ }^{10}$. Based on this premises, this work aimed to investigate the effects of the diamond film on Ti6Al4V surface using mesenchymal cells models in vitro, namely fibroblast and pre-osteoblast cells ${ }^{11}$. Characterizations of material surface 
were performed with X-ray diffraction (XRD) and Raman backscattering spectroscopy, both used to evaluate the film, atomic force microscopy (AFM) and confocal laser profilometer were used to evaluate the roughness performed prior to the cell culture procedures ${ }^{12}$. Furthermore, scanning electron microscopy (SEM) was performed to assess cell morphology and organization on surface.

\section{Material and Methods}

\subsection{Diamond film deposition and characterizations}

All samples of Ti6Al4V alloy grade 5 were cut with $1 \mathrm{~mm}$ thickness in 12x12 mm. According to the manufacturer, some mechanical properties are as follows: chemical composition of $6,0 \%-\mathrm{Al}, 0,3 \%-\mathrm{Fe}, 0,2 \%-\mathrm{O}, 0,01 \%-\mathrm{V}$ and $90 \%$-Ti; ultimate tensile strength of $877 \mathrm{MPa}$; yield tensile strength of $815 \mathrm{MPa}$; and elongation of $10 \%$. In order to enhance film adhesion on metallic surface, Ti6Al4V samples were mechanically treated by shot peening with the goal to increase the hardness, and this is due the impact of non-deformable steel spheres in to the surface. The deposition of diamond film was performed for $4 \mathrm{~h}$ in a chemical vapor deposition reactor activated by hot filament using gases mixture of $1 \%$ methane and $99 \%$ hydrogen at $100 \mathrm{sccm}$ flow rate and 20 Torr of pressure ${ }^{9}$. Samples of polished $\mathrm{p}$ type $\mathrm{Si}$ (100) were put together inside the deposition chamber beside the titanium alloy samples only for comparative analysis, since silicon substrate is largely used when diamond film is studied. All of them were treated in a process known as "seeding" which consists in ultrasonically bath using solution of $0.25 \mu \mathrm{m}$ diameter diamond powder dissolved in pure hexane during $1 \mathrm{~h}$, followed by cleaning in acetone for $15 \mathrm{~min}$. The seeding efficiency for diamond deposition can be verified in the article "Dispersion liquid properties for efficient seeding in CVD diamond nucleation enhancement" done by R. C. Mendes de Barros et al. (1996) ${ }^{13}$. Sample support was mounted to keep titanium and silicon sample at $3 \mathrm{~mm}$ distance under three tungsten filaments with $123 \mu \mathrm{m}$ of diameter. The filament temperature of $2100^{\circ} \mathrm{C}$ was measured by optical pyrometer while substrate temperature was $700^{\circ} \mathrm{C}$, and measured by $\mathrm{k}$ type thermocouple situated under the sample. All the coated and uncoated samples were labelled according to Table 1.

\subsection{Cell seeding and culture}

Human Gingival Fibroblasts (HGF) and mouse MC3T3-E1-pre-osteoblasts cells were used in cell culture experiments. The cells were cultivated in humid atmosphere at $37^{\circ} \mathrm{C}$ with $5 \% \mathrm{CO}_{2}$ in Dulbecco's modified Eagle medium supplemented with $15 \%$ fetal bovine serum (FBS) and alpha-men medium supplemented with 10\% FBS (HGF and MC3T3-E1, respectively). Gentamicin at $0.4 \%$ final concentration was used to avoid microbial contamination and cells were routinely sub cultivated. In order to evaluate the effects of Ti6Al4V surface treatments on cells, initially all the metal samples were subjected to ultrasonic cleaning and series of consecutive washes with acetone, isopropyl alcohol P.A 95\%, ethanol, and distilled deionised ultrapure water ( $15 \mathrm{~min}$ each), following incubation at $50^{\circ} \mathrm{C}$ for $24 \mathrm{~h}$. Afterwards, for the experimental sets described in Table 1 were used five samples in each condition. Finally cell seeding was performed for the assays indicated next.

\subsection{Evaluation of cell viability and morphology}

Cells at $80 \%$ monolayer confluence were serum-starved for $24 \mathrm{~h}$ prior to seeding. Subsequently, cells were dissociated with $0.05 \%$ trypsin, ressuspended in Dubecco's Phosphate Buffer Saline (DPBS), and seeded at $5 \times 10^{5}$ cells per well in which samples were carefully allocated. After incubation for $24 \mathrm{~h}$, the cells were subjected to an initial assessment of cell number and viability by the Trypan Blue dye-exclusion technique using haemocytometer and evaluation under conventional light microscopy with a Nikon Eclipse TS100 inverted microscope. Subsequently, the cells in suspension were seeded in a 96 wells plate and subjected to the CellTiter $96^{\circledR}$ Aqueous Assay (Promega, Madison, WI, USA), as instructed by the manufacturer. Absorbance readings were carried out with at $490 \mathrm{~nm}$ on iMark Absorbance Microplate Reader device (Bio-Rad Laboratories, Hercules, CA, USA).

The morphology and cell organization was assessed after seeding cells at $0.75 \times 10^{5}$ cells on the surface of film-covered and uncovered metal samples and cell culture for $24 \mathrm{~h}$. Afterwards, titanium samples were dipped into $2.5 \%$ glutaraldehyde solution for cell fixation and preservation, aiming the scanning electron microscopy (SEM). Fixed cells on to the surfaces were observed using Hitachi S-3400 VP-SEM scanning electron microscopy.

Table 1. Code description, treatment/deposition and roughness of the surface.

\begin{tabular}{cllc}
\hline Code & Sample description & Treatment & $\begin{array}{c}\text { Roughness } \pm \text { SD } \\
(\mu \mathrm{m})\end{array}$ \\
\hline S & Smooth Ti6A14V & No surface treatment. Sample as received from the manufacture. & $0.82 \pm 0.01$ \\
R & Rough Ti6A14V & With shot peening treatment without coating & $4.95 \pm 0.85$ \\
D & Diamond film on rough Ti6Al4V & With shot peening treatment with coating & $4.47 \pm 1.01$ \\
Si & Diamond film on silicon substrate & Control sample (reference) & $0.41 \pm 0.04$ \\
\hline
\end{tabular}




\section{Results and Discussion}

\subsection{Morphology of the titanium surface}

The region marked as " 1 " in Fig. 1 shows that the early growth of the film does not form homogeneous interface. Probably due nucleation spots created during seeding procedure described here in the 2.1 material and methods section. Also, columns (vertical expansion growth) of diamond were formed as showed in " 2 ", and that happened after the coalescence (horizontal expansion growth) of the diamond seeds. These columns cause the so-called internal stress of the film, or only intrinsic stress. However, in the sample " $R$ ", as can be seen in a top view from the image in Fig. 2, it is clear that in " 3 " there is a plastic deformation caused by sphere impact, causing a high alteration of the morphology and resulting in a rough surface. Also, in the Fig. 2, it is possible to check in "4" small cracks. Fig. 3 shows the sample "D" which is the rough titanium after the deposition of diamond. It is interesting to note that the surface is completely covered, that is including inside the pores occurred diamond grain formation. Furthermore, the diamond grains provided a new texture to the surface. Each diamond face has approximately $0.5 \mu \mathrm{m}$ of length. Note that in this sample the small cracks in the substrate mentioned above are no longer visible. Morphological characteristics of the diamond face are being shown in Fig. 4. The atomic force microscopy images are to the right of Fig. 4, the same image is being shown in two and three dimensions. There, the estimation of peak and valley of the diamond grain are measured by AFM, and is approximately the same in other areas scanned in other samples. Here, it was not made a statistical survey, because the heterogeneity of the surface. Better statistic tools can provide more accurate values, just qualitative information is being considered here. The rough samples used here have deep pores, and this did not allow the views for larger areas, due to the limitation of AFM technique and the possibility to damage the cantilever. In Fig. 5 are placed the confocal profilometer images for samples (a) "S", (b) "R", (c) "D" and (d) "Si". The sample "S" has surface marks in the longitudinal direction originally caused by the manufacture of the titanium alloy sheet. The "R" sample refers to a sample of titanium after blasting. Note that there are no longer longitudinal marks direction, instead an irregular shape can found. In the sample " $D$ ", the same shape of the surface " $R$ " are present, however, it is observed that the diamond grain gives to the surface some spots of rounding. In "Si", it is clear that the diamond film shape follows the surface, as expected.

\subsection{Film characterization by Raman backscattering spectroscopy and X-rays diffraction}

Fig. 6 shows the XRD spectra using $\mathrm{Cu}-\mathrm{K} \alpha$ radiation. The spectrum of diamond film, used as reference, has the

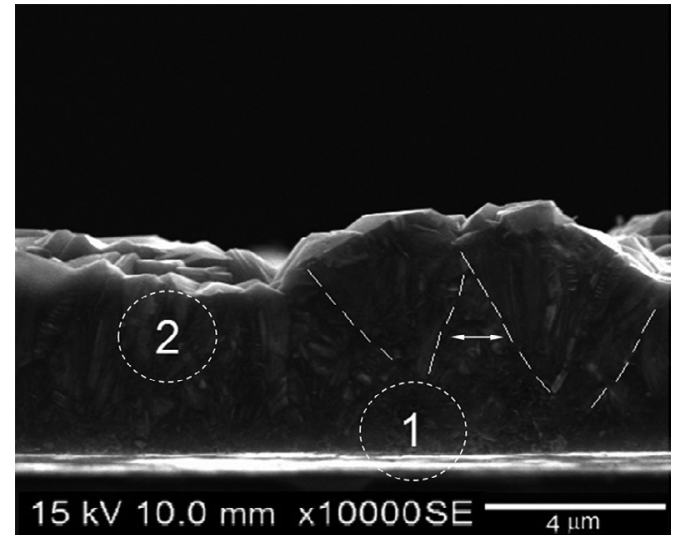

Figure 1. Diamond film thickness on Ti6Al4V sample. Region "1" shows that there is a heterogeneous interface between the film and substrate, while in "2", it is possible to verify a columnar diamond shape.

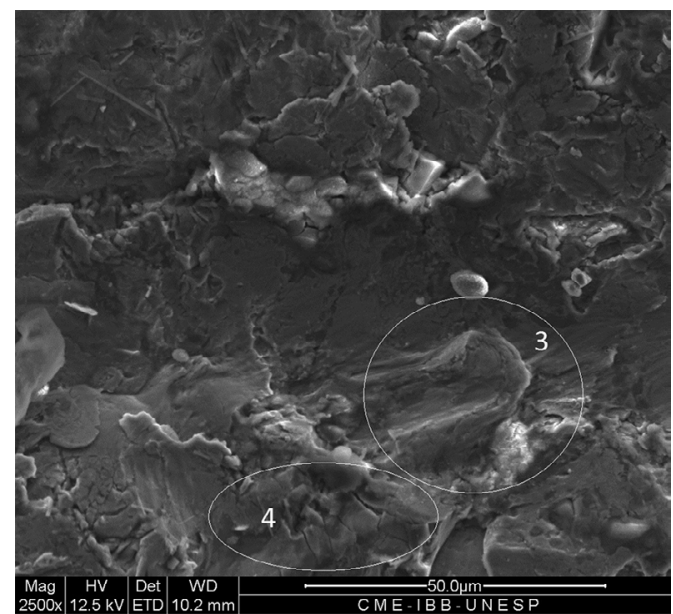

Figure 2. Surface of sample "R" after process of increasing roughness by blasting. In " 3 ", plastic deformation caused a drag of the surface material, while in " 4 " can be seen small cracks probably occurred due to the elevation of local stress.

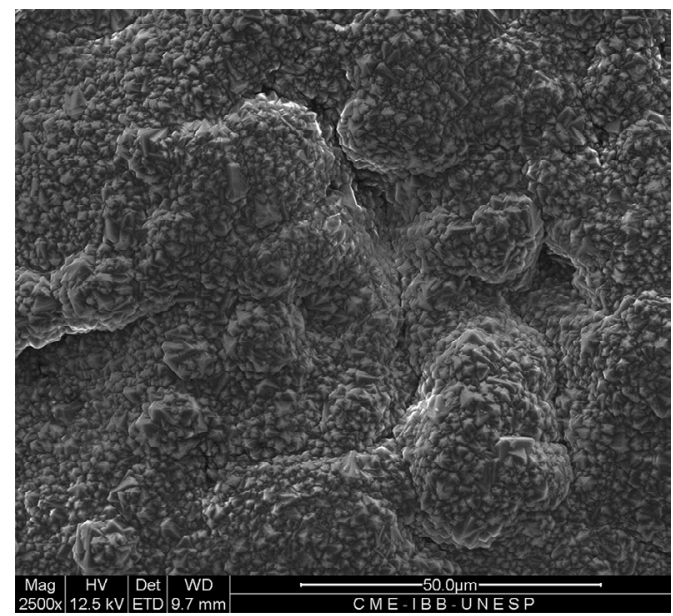

Figure 3. Surface of the sample "D". Note that the surface is fully covered with diamond grains, including within the pores can be seen that there were the formation of grains. 

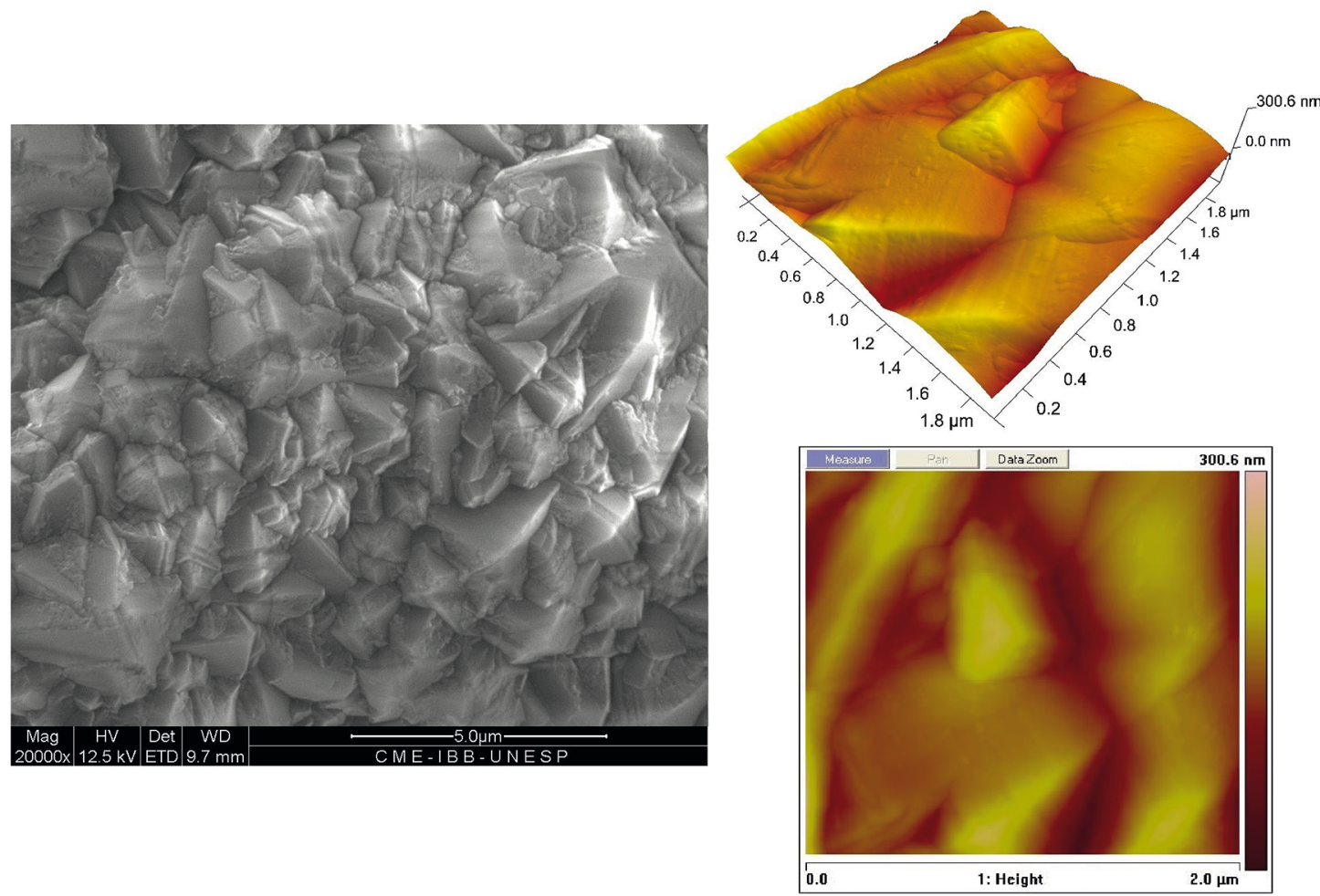

Figure 4. Morphology of the film obtained by atomic force microscopy. The scanning is $1.8 \mathrm{X} 1.8 \mathrm{X} 0.3 \mu \mathrm{m}$. The face of the diamond has a preferred plan with a seemingly tetrahedral shape.

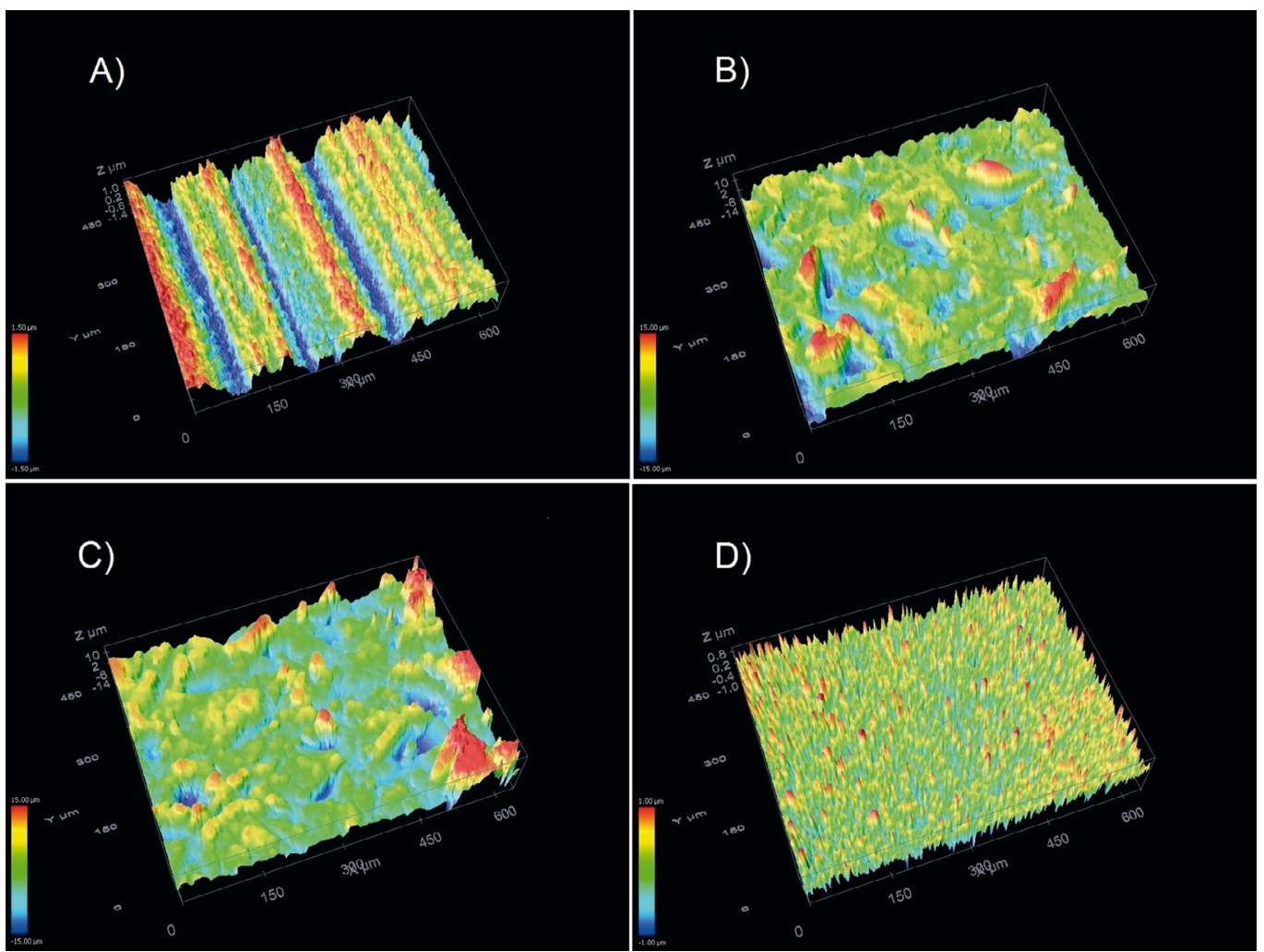

Figure 5. Images obtained by confocal profilometer of morphology sample surface in $600 \mathrm{X} 600 \mathrm{X} 10 \mu \mathrm{m}$ scanning area. (A) "S" sample (b) "R" sample (c) "D" sample and (d) "Si" sample. 

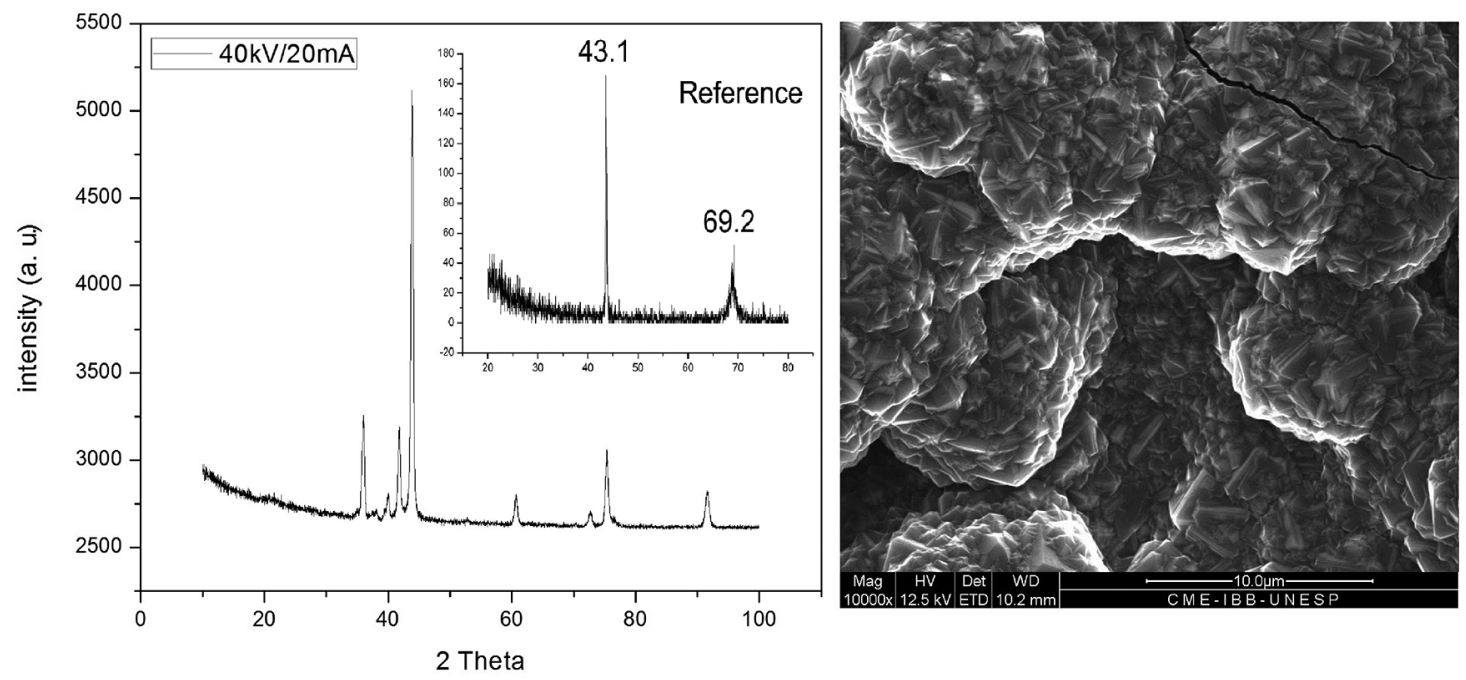

Figure 6. X-ray diffraction spectra obtained from the coating (external) and a natural diamond (internal). Some additional peaks at $35^{\circ}$, $39^{\circ}, 41^{\circ}, 60^{\circ}, 72^{\circ}, 76^{\circ}$ and $91^{\circ}$ indicate the distortions in the crystal lattice, which may explain the high internal stress of the coating. Some spots of cracks were identified in the sample and can be seen on the image of the spectra.

regular peak at $43.1^{\circ}$. The other peak at $69.2^{\circ}$ is normally identified when silicon substrate is used. The spectrum of the sample "D" shows higher peak intensity relating to the diamond (111) and also other phases with lower intensity peaks for diamond $(220)$ at $75^{\circ}$ and $(331)$ at $91^{\circ}$. In addition, it is possible that "TiC" phase is identified by $41^{\circ}$ and $61^{\circ}$ peaks ${ }^{14,15}$ and can be assigned to an interface-forming effect. Due the excess of internal film stress, these mentioned phases might be related to the cracks observed in the film and issues related to the internal stress strongly affect its integrity and adhesion. Analysis by Raman backscattering spectroscopy allows an understanding of carbon-based materials structure. These analysis were performed using $\lambda=257 \mathrm{~nm}$. Three example of Raman backscattering spectra from " $D$ " sample is shown in Fig. 7. The presence of characteristic peak of natural diamond is positioned in $1332 \mathrm{~cm}^{-1}$. It is possible to notice a shift of $5 \mathrm{~cm}^{-1}$ in the film used here. Also, it is known that the diamond polycrystalline spectrum has a band centred at $1550 \mathrm{~cm}^{-1}$, which has been assigned to scattering of $\mathrm{sp}^{2}$ carbon bonding ${ }^{16}$.

\subsection{Cell viability and morphological analysis}

Pre-osteoblastic (MC3T3-E1) cells were cultivated on all surfaces and for each experimental condition previously indicated. As observed in Fig. 8, no significant changes in cell viability were observed comparing the distinct surfaces used. The chemical nature of the different surfaces studied had no influence on the cells. Apparently, for the surface as received from the titanium manufacture the ultrasonic cleaning process assists the maintenance of the cells on that alloy. The treatment required before the deposition process called shot peenig did not decrease cell viability, however, alloy debris was observed. It was noted the possibility of

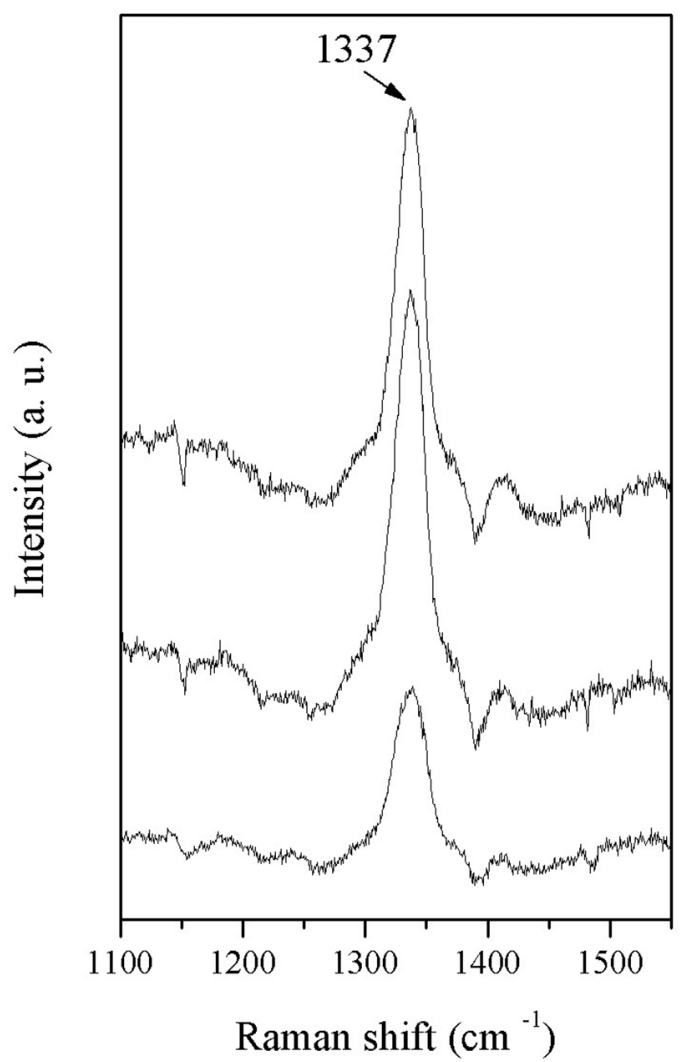

Figure 7. Raman scattering spectrum of sample "D". A deviation from the natural diamond $\left(1332 \mathrm{~cm}^{-1}\right)$ of $5 \mathrm{~cm}^{-1}$ is an indicative signal of high internal residual stress of the film. Factors such as deposition time and surface preparation can explain the high internal stress of the film. 


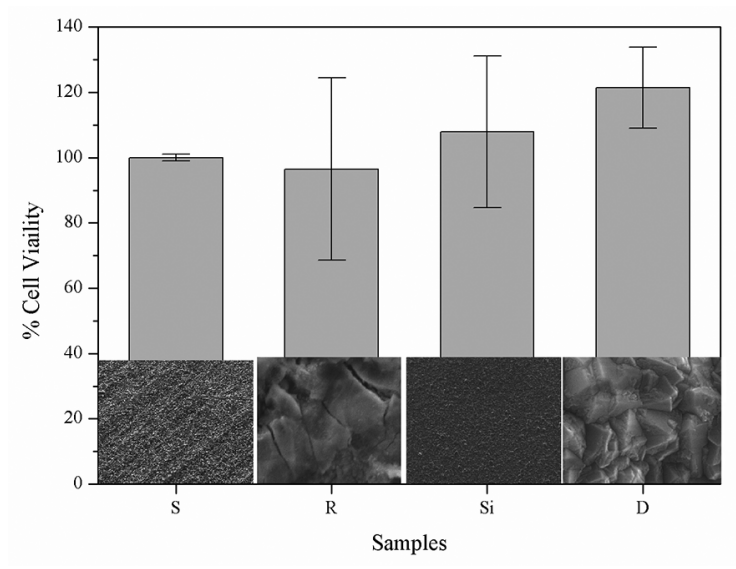

Figure 8. Scatter plot for MC3T3-E1 (mouse pre-osteoblastic) cells viability. The cells were cultivated on Ti6Al4V surface without treatment (S; negative control), rough Ti6Al4V (R), rough Ti6Al4V covered with diamond film (D) or a silicon substrate covered with a diamond film (Si). Absorbance values were converted to percentage, and the negative control (Ti6Al4V without treatment) represents $100 \%$ of cell viability. The results presented include data for three independent experiments with three ( $\mathrm{S}$ and $\mathrm{R}$ ) or six (D and $\mathrm{Si}$ ) samples each. wear protection for the coated titanium surface. Also, one advantage of having the film is the protection of the surface against release of debris. Nevertheless, the results of the cell viability tests demonstrate that the cells have grown on different surfaces. Both the substrate with the diamond film and the titanium surface were susceptible to biocompatibility. Fig. 9 and Fig. 10 shown representative results of SEM for pre-osteoblastic cells (MC3T3-E1; Fig. 9) and human gingival fibroblasts (HGF; Fig. 10). Overall, cells succeeded to cover both the non-treated and the diamond-treated Ti6Al4V surfaces. However, cells seeded on rough titanium without the diamond film layer (Fig. 9 and 10, left panels) showed a higher number of cytoplasm projections compared to cells seeded on the metal layered with the diamond (Fig. 9 and Fig. 10 , right panels). Furthermore, the cellular monolayer was more uniform and complete for both cells types evaluated on diamond-treated samples; in this regard, fibroblasts (HGF) cells almost reached complete confluence over the treated Ti6Al4V surface. This result suggests that the diamond film improved cell adhesion and migration on the titanium surface, improving the compatibility of the metal-tissue interface.
A)

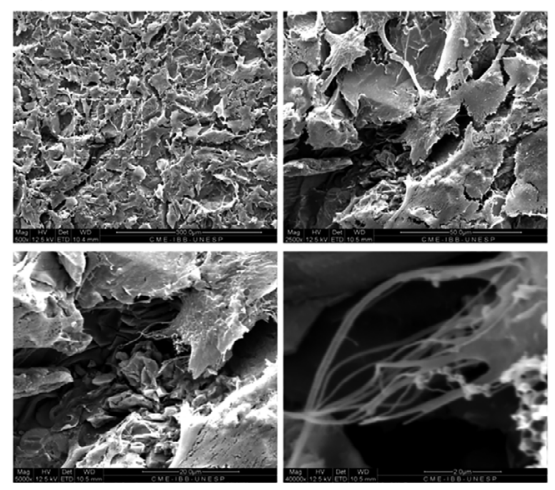

B)

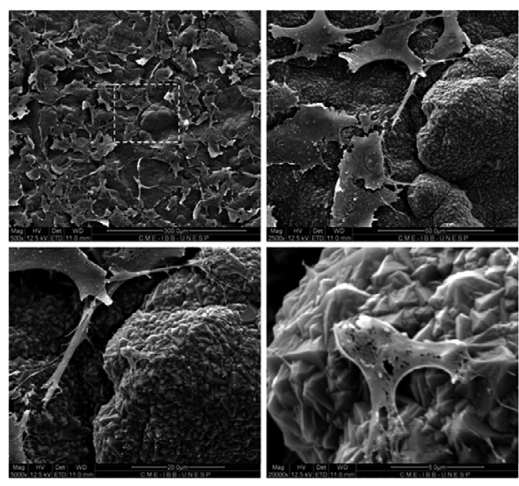

Figure 9. Scanning electron microscopy of osteoblast cells on rough titanium without (left) or with (right) the diamond film.

A)
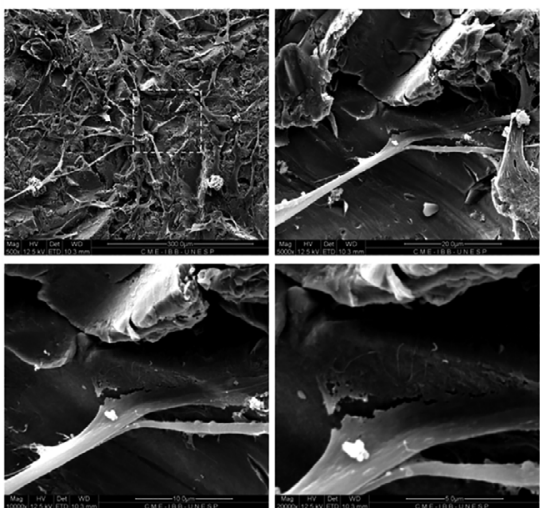

B)

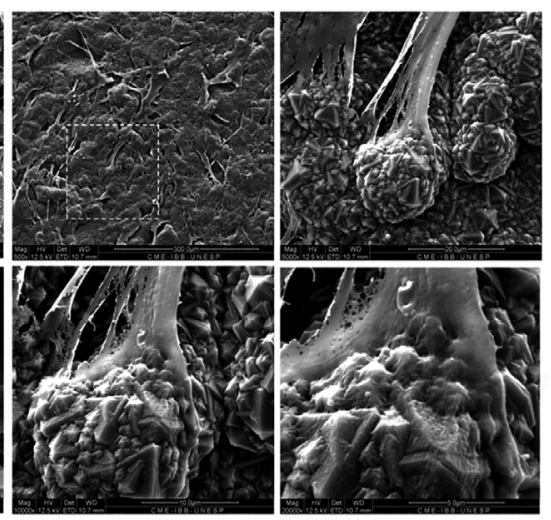

Figure 10. Scanning electron microscopy of fibroblast cells on rough titanium without diamond film. 


\section{Conclusions}

The deposition of diamond on rough titanium is possible with thickness of two micrometers approximately, hiding any crack or debris. The diamond film follows the surface structure: for instance, titanium pores were coated with diamond, demonstrating the effectiveness of the covering process for the entire surface. The atomic force microscopy and profilometry analysis allowed assessing changes in the surface shape and how the treatment affected the roughness.

The preliminary assessment of cell viability on the Ti6A14V surfaces indicated that the diamond film treatment does not increase cytotoxicity in either cell models used (MC3T3-E1 mouse pre-osteoblasts or HGF human gingival fibroblasts). Although the morphological evaluation of cells in vitro by SEM does not allow direct or precise measurement of cell adhesion capabilities, it provides some information about the cell adhesion and growth features of cells seeded on non-biological surfaces in a controlled environment. The cells seeded over the diamond-treated titanium surface evolved more satisfactory than cells seeded on non-treated Ti6A14V, considering the time frame and conditions employed.

In conclusion, these preliminary observations suggest that the diamond film may be a good alternative for improvement of the implant/tissue interface on health care applications of titanium, and it deservers further investigation.

\section{Acknowledgments}

W. M. Silva and the authors would like to thank the financial support of grant $n^{\circ}$ 2015/20438-6, São Paulo Research Foundation (Fundação de Amparo à Pesquisa do Estado de São Paulo-FAPESP).

\section{References}

1. Lawrence J, Hao L, Chew HR. On the correlation between Nd:YAG laser-induced wettability characteristics modification and osteoblast cell bioactivity on a titanium alloy. Surface and Coatings Technology. 2006;200(18-19):5581-5589.

2. de Viteri VS, Barandika G, Bayón R, Fernández X, Ciarsolo I, Igartua A, et al. Development of Ti-C-N coatings with improved tribological behavior and antibacterial properties. Journal of the Mechanical Behavior of Biomedical Materials. 2016;55:75-86.

3. Olivares-Navarrete R, Gittens R, Schneider JM, Hyzy SL, Haithcock DA, Ullrich PF, et al. Osteoblasts exhibit a more differentiated phenotype and increased bone morphogenetic protein production on titanium alloy substrates than on polyether-ether-ketone. The Spine Journal. 2012;12(3):265-272.

4. Olivares-Navarrete R, Hyzy SH, Gittens RA, Schneider JM, Haithcock DA, Ullrich PF, et al. Rough titanium alloys regulate osteoblast production of angiogenic factors. The Spine Journal. 2013;13(11):1563-1570.

5. Goriainov V, Cook R, Latham JM, Dunlop DG, Oreffo ROC. Bone and metal: An orthopaedic perspective on osseointegration of metals. Acta Biomaterialia. 2014;10(10):4043-4057.

6. Rubstein AP, Makarova EB, Trakhtenberg IS, Kudryavtseva IP, Bliznets DG, Philippov YI, et al. Osseointegration of porous titanium modified by diamond-like carbon and carbon nitride. Diamond and Related Materials. 2012;22:128-135.

7. Rodrigues AA, Baranauskas V, Ceragioli HJ, Peterlevitz AC, Santos Junior AR, Belangero WD. Preliminary viability studies of fibroblastic cells cultured on microcrystalline and nanocrystalline diamonds produced by chemical vapour deposition method. Materials Research. 2013;16(1):252-258.

8. Swiatek L, Olejnik A, Grabarczyk J, Jedrzejczak A, SobczykGuzenda A, Kaminska M, et al. Multi-doped diamond like-carbon coatings (DLC-Si/Ag) for biomedical applications fabricated using the modified chemical vapour deposition method. Diamond and Related Materials. 2016;67:54-62.

9. Silva WM, Ferreira NG, Travello J, Almeida EC, Azevedo AF, Baldan MR. Dependence of diamond nucleation and growth through graphite etching at different temperatures. Diamond and Related Materials. 2007;16(9):1705-1710.

10. Yang L, Sheldon B, Webster TJ. The impact of diamond nanocrystallinity on osteoblast functions. Biomaterials. 2009;30(20):3458-3465.

11. Caparrós C, Guillem-Martí J, Molmeneu M, Punset M, Calero JA, Gil FJ. Mechanical properties and in vitro biological response to porous titanium alloys prepared for use in intervertebral implants. Journal of the Mechanical Behavior of Biomedical Materials. 2014;39:79-86.

12. Randeniya LK, Bendavid A, Martin PJ, Amin MR, Rohanizadeh $\mathrm{B}$, Tang F, et al. Thin-film nanocomposites of diamond-like carbon and titanium oxide; Osteoblast adhesion and surface properties. Diamond and Related Materials. 2010;19(4):329-335.

13. Mendes de Barros RC, Corat EJ, Ferreira NG, Souza TM, TravaAiroldi VJ, Leite NF, et al. K. Dispersion liquid properties for efficient seeding in CVD diamond nucleation enhancement. Diamond and Related Materials. 1996;5(11):1323-1332.

14. Woo HK, Lee ST, Lee CS, Bello I, Lam YW. Diamond films grown by hot filament chemical vapor deposition from a solid carbon source. Journal of Vacuum Science \& Technology A: Vacuum, Surfaces, and Films. 1997;15(6):2988-2992.

15. Liu D, Zhou Y, Song X, Huo W, Feng J. Interfacial microstructure and performance of nano-diamond film/Ti-6Al-4V joint brazed with AgCuTi alloy. Diamond and Related Materials. 2016;68:42-50.

16. Wagner J, Ramsteiner M, Wild C, Koidl P. Resonant Raman scattering of amorphous carbon and polycrystalline diamond films. Physical Review B. 1989;40(3):1817-1824. 